\title{
Bioengineering for health: development of a knowledge- based for the benefit of environmental health care
}

\author{
Hosam Bayoumi Hamuda* \\ Environmental Microbiologist and Soil Biotechnologist, Óbuda University, Hungary
}

Due to the great industrial revolution, excessive using of the agricultural chemicals like pesticides and fertilisers, the effects of the greenhouses, etc. which cause the environmental contamination with high levels of organic and inorganic toxicants, including heavy metals, emitted gases and pharmaceuticals. It was a great task to search for how to take care for our environment and human health.

Bioengineering for health includes the development of basal concepts in engineering, biology and medicine to develop innovative approaches and new devices, materials, processes, etc. and monitoring systems for the assessment and evaluation of technology; for prevention, diagnosis, and treatment of disease; for patient care and rehabilitation and for improving medical practice and health care delivery not only for human treatment but also in similar case to keep our environment healthy by means of clean and clear. One of our objectives is to develop high quality of health for our biosphere.

After 38 years of experimental research we found that now is the time for rewriting the future of our Planet through the cooperation between biology, engineering and medicine to promote the visibility and recognition of bioengineering for health and to inform national, European and global policy makers as well as other relevant stakeholders about the current situation and future perspectives of this multidisciplinary domain so important for our society.

Now the daily problems and challenges of a decreasing and ageing population for example in Europe that needs a policy and technology of growth to improve competitiveness and ensure economic stability with high quality in achieving the Lisbon goals. The needs for innovation and development in biomedical engineering and (bio)technology in overall life aspects are necessary for increasing socio-economic importance for the health of human and then for the environment. Bioengineering for human and environmental health assumes an increasingly important significant role as an integrative agenda involving all technical sectors for example industry, agriculture, education, research and health care organizations.

Globally, the health-related industries in Europe are losing in competitiveness compared to other regions of the world. This is due to the weak relationship between the biological, engineering and medical associations.

Bioengineering for environmental and human health research and innovation combine the technical, social and economic benefits. This can be done through modernising methods used for monitoring, prevention, diagnosis and treatments, it creates greater significant efficiency and savings in the health systems for the human and the environment and great benefits can be achieved with respect to high quality of life. Bioengineering for Health is intimately engaged in developing the required technological backbone for this ambitious knowledge based approach to health care for the human as well as the environment.

Distinguish in medical and biological engineering experimental technics and education has the capacity to be the dynamic and effective engine for the development of the knowledge and economy in the global society and the indicator point for international talents. Finally, we can come to some considerations:

- Include bioengineering for human and environmental health as a key strategic agenda for making our future Framework Programmes.

- Increase the investment by providing special actions for experimental research, innovation and technology transfer aimed to promote a wider adoption of global health care technology systems for human and total environment.

- Establish the global Institutes of human and environmental health including an Institute for Medical and Biological Engineering Research.

- Promote and support education, training and professional development of specialists necessary to carry out these activities.

Based on the above facts our research activities were concentrated on the monitoring the rate of environmental contamination regarding the soil and water quality and how to develop healthy environment which automatically increase the quality of human health.

Our research interest was for investigations on the role of waste management on soil quality, fertility, the crop production and environmental impacts related to the application of organic wastes to soils to assess: (1) recycling of nutrients (namely carbon, nitrogen and phosphorus, sulphur) via crop residues or organic waste amendments; (2) chemical, biochemical and microbiological methods to assess $\mathrm{C}, \mathrm{N}$, $\mathrm{P}$ and $\mathrm{S}$ mineralization from organic amendments; (3) application of

Correspondence to: Prof. Hosam Bayoumi Hamuda, Environmental Microbiologist and Soil Biotechnologist, Óbuda University, Hungary; E-mail: hosameaf@gmail.com

Key words: Environmental health, Soil Biotechnology, Soil Protection, Soil Sustainable, Soil Biodiversity, Plant Growth-Promoting Rhizobiomes (PGPR), Colonization of PGPR microbial Inoculant in rhizosphere, Metal oxides nanoparticles, Econanotoxicology, Water quality of Danube River at Budapest region

Received: November 02, 2016; Accepted: November 17, 2016; Published: November 21, 2016 
C, N, P and S models to meet the environmental diagnosis requirements; (4) approaches to $\mathrm{N}$ management in order to improve $\mathrm{N}$ use efficiency; (5) (bio)indicators of water and soil quality; (6) diagnostics tools for fertilisers recommendation and fertilisation strategies to reduce environmental impacts; (7) assessment of Plant Growth-Promoting Rhizobiomes (PGPR) for crop quality; (8) assess the influence of Nitrification Inhibitors on crop yield and soil mineral $\mathrm{N}$ dynamics before and after incorporation with wastewater sludge; (9) test the influence of wastewater sludge treatment on the potential of $\mathrm{C}$ and $\mathrm{N}$ mineralization and $\mathrm{CO}_{2}$ and $\mathrm{N}_{2} \mathrm{O}$ emissions after soil incorporation; (10) examine the influence of roots and root exudates on $\mathrm{N}$ mineralization potential of native soil organic matter added to the soils in un-cropped and cropped soils; (11) monitorization of organic matter fractionation, measurements of rhizosphere and soil microbial biomass; (12) evaluate the influence of each treatment on soil C, N, P and $S$ dynamics, soil microbial biomass, soil enzymatic activities in wastewater sludge or compost treated soils; (13) impact of metal oxides nanoparticles $\left(\mathrm{Al}_{2} \mathrm{O}_{3}, \mathrm{FeO}_{2}, \mathrm{TiO}_{2}, \mathrm{CuO}\right.$ and $\left.\mathrm{ZnO}\right)$ on soil useful microorganisms (symbiotic $\mathrm{N}_{2}$-fixing bacteria) and legume plant growth.

Examine the structure and function of the root systems and microbial composition in the organic and inorganic polluted environment. This investigation was carried out to study the:

- Improvement of plant production by soil inoculation with some useful microorganisms.

- Soil microorganisms and using their metabolites to protect plant against phytopathogens.

- Biodegradation of toxic organic materials using somecharacterized microorganisms, and manipulate the microorganisms and their enzymatic activities to increase the agricultural products.

- Interactions between wastewater sludge, pesticides, and other toxicants and soil beneficial microorganisms.

- Biodiversity of microbial community stands to different degree influenced by environmental pollution.

Then, the research work was directed to investigate the impacts of industrial, communal and agricultural wastes on the Plant - Soil - Microbe system based on their content level of heavy metals, organic pollutants, etc. The investigations were on concentrated on:

- The plant production (dry matter content, plant height, essential metal contents, etc.),

- Microbial contents (aerobic heterotrophic bacteria, spore-forming bacteria, actinobacteria, microscopic filamentous fungi, yeasts, diazotrophic microbes, aerobic cellulose decomposers, phosphate solubilizing bioagents, lytic enzyme, siderophore, $\mathrm{CN}$ producers, rate of $\mathrm{CO}_{2}$ release, ratio between Gram positive bacteria to Gram negative.

- Soil enzymatic activities (dehydrogenase, catalase, protease, urease, phosphatase, $\beta$-glycosidase, aryl-sulphatase, cellulase) and the total biological activity in term of FDA.

- The results demonstrated that the plant (root and shoot) growth and development were healthier with high nutritive value at the wastewater sludge range from 30 to $60 \%$ in soil. The plant was more protected against some phytopathogens. Soil quality and fertility were more valuable.

The above gives examples of the possible benefits of junction between biological science and engineering for monitoring the environmental contamination and by what aspects could improve the health of the environment. If it is carried out, then we will improve the human health care. So, the partnership between Biology, Engineering and Medicine will eventually enable the total design-based, predictive modification of environment important to us, including, the human health care. Finally, the goal is to better understand, replace or fix a target system to ultimately improve the quality of health care of the environment and human.

Since 2010, we organise 7 international conferences related to Global Environmental Changes and Environmental Health:

- $7^{\text {th }}$ ICEEE-2016 International Conference: „Global Environmental Changes and Environmental Health: Environmental and Economic Impact on Sustainable Development", $17^{\text {th }}-19^{\text {th }}$ of November 2016, Budapest, Hungary.

- $6^{\text {th }}$ ICEEE-2015 International Conference: “Global Environmental Changes and Environmental Health: Progress and Challenges" $19^{\text {th }}-21^{\text {st }}$ November 2015, Budapest, Hungary

- $5^{\text {th }}$ ICEEE-2014 International Conference "Global Environmental Change and Population Health: Progress and Challenges" $19^{\text {th }}-21^{\text {st }}$ November 2014, Budapest, Hungary.

- $4^{\text {th }}$ International Conference of ICEEE “To Protect our Global Environment for Future Generations". $20^{\text {th }}-22^{\text {nd }}$ November 2013 , Budapest, Hungary.

- $3^{\text {nd }}$ International Joint Conference on Environmental and Light Industry Technologies, $21^{\text {st }}-22^{\text {nd }}$ November 2012, Budapest, Hungary.

- $2^{\text {nd }}$ International Conference for Development of Environmental Engineering Education, $21^{\text {st }}-22^{\text {nd }}$ November 2011, Budapest, Hungary.

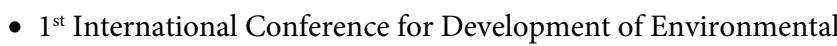
Engineering Education, $18^{\text {th }}-19^{\text {th }}$ November, 2010, Budapest, Hungary.

Copyright: (2016 Hamuda HB. This is an open-access article distributed under the terms of the Creative Commons Attribution License, which permits unrestricted use, distribution, and reproduction in any medium, provided the original author and source are credited. 